\title{
MURAL SEBAGAI SOSIALISASI PERILAKU HIDUP BERSIH DAN SEHAT DI KECAMATAN KARAWACI, KOTA TANGERANG, PROVINSI BANTEN
}

\author{
Budi Karyanto $^{1^{*}}$, Meidy Franky Lombogia ${ }^{2}$, Adya Hermawati ${ }^{3}$ \\ ${ }^{1}$ Program Studi Manajemen Sekolah Tinggi Ilmu Ekonomi Bisma Lepisi \\ ${ }^{2}$ Akademi Sekretari dan Manajemen Lepisi \\ ${ }^{3}$ Program Pasca Sarjana Universitas Widyagama Malang \\ *Email Korespondensi : budi@lepisi.ac.id
}

\begin{abstract}
ABSTRAK
Mural adalah gambar atau lukisan di atas media dinding atau media luas lainnya yang bersifat permanen. Mural yang berupa Perilaku Hidup Bersih dan Sehat (PHBS) di Kecamatan Karawaci, Kota Tangerang bertujuan untuk membantu pemerintah Kota Tangerang dalam sosialisasi bagi warga masyarakat Kota Tangerang supaya berperilaku hidup bersih dan sehat. Kegiatan Pengabdian kepada Masyarakat kali ini memanfaatkan dinding rumah warga untuk melukis mural yang dapat dijadikan sarana sosialisasi dengan cara mengingatkan warga masyarakat untuk hidup bersih dan sehat. Selain itu, mural juga dapat digunakan untuk spot swafoto atau rekreasi bagi masyarakat.
\end{abstract}

Kata kunci: perilaku hidup besih dan sehat, mural, pengabdian kepada masyarakat

\section{ABSTRACT}

A mural is a permanent image or painting on a wall or other broad media. The mural in the form of Clean and Healthy Living Behavior (PHBS) in Karawaci Subdistrict, Tangerang City, aims to help the Tangerang City government in socialising Tangerang City residents to have a clean and healthy lifestyle. This time, Community Service activities use the walls of residents' houses to paint murals which can be used as a means of socialisation by reminding people to live clean and healthy. Besides, murals can also be used as selfie or recreation spots for the community.

Keywords: clean and healthy life behaviour, graffiti, community service

\section{PENDAHULUAN}

Kecamatan Karawaci, Kota Tangerang merupakan kawasan yang padat penduduk. Kota Tangerang yang merupakan salah satu penyangga ibukota negara selain dikenal sebagai kota seribu industri juga merupakan kota yang padat penduduk baik di perumahan maupun di perkampungan. Padatnya penduduk menyebabkan kurangnya kawasan terbuka hijau sebagai sarana rekreasi, olahraga dan swafoto. Dengan minimnya kawasan terbuka hijau maka lokasi/spot sekecil apapun sebenarnya bisa dijadikan media atau sarana untuk rekreasi. Seni mural atau grafiti sangat memungkinkan untuk dikreasikan di lokasi/spot yang kecil sekalipun. Tembok/dinding merupan media yang ideal untuk melakukan murat atau lukiasn dinding. Mural juga bisa dijadikan sarana edukasi bagi masyrakat dengan menyajikan lukisan yang bersifat ajakan, himbauan ataupun informasi dari pemerintah bagi warga masyarakat di Kecamatan Karawaci Kota Tangerang Banten (Williamson, 1999; Lilih, 2009; Endriawan, Maulana and Sadono, 2017; Fatin, 2018; Suastika, 2018; Luthfi, 2020)

Mural berasal dari bahasa latin yaitu dari kata "Murus" yang berarti dinding. Secara luas pengertian mural adalah menggambar atau melukis di atas media dinding, tembok atau media luas lainnya yang bersifat permanen.Seni mural sebenarnya sudah ada sejak jaman dahulu kala. Bahkan jika ditilik dari sejarah mural, mural sudah ada sejak 31.500 tahun yang lalu tepatnya pada masa prasejarah. Pada masa itu terdapat sebuah lukisan yang menggambarkan sebuah gua di Lascaux yaitu daerah Selatan Prancis. Mural 
yang dibuat pada masa prasejarah tersebut menggunakan sari buah sebagai cat air (karena pada masa prasejarah belum ada cat). Pada masa prasejarah, negara yang paling banyak memiliki lukisan dinding atau mural tidak lain yaitu Prancis. Salah satu mural atau lukisan dinding yang paling terkenal pada saat itu yaitu mural karya Pablo Picasso. Pablo Picasso membuat sebuah mural yang dinamakan Guernica atau Guernica y Luno. Mural ini dibuat pada saat terjadinya peristiwa perang sipil di Spanyol pada tahun 1937.

Mural di Indonesia sudah sangat lama ada bahkan ribuan tahun yang lalu sudah ada. Hal ini bisa kita lihat dari dinding - dinding goa pada stalaktit dan stalakmit dimana manusia dahulu (manusia purna) sudah melukis dengan bahas alami dari getah pohon maupun darah binatang. Gambar lukisan tangan dan binatang berumur sekitar 39.000 tahun di Maros Sulawesi Selatan seperti pada Gambar 1 (Gazali, 2017, 2017; Ifwandi, 2020; Luthfi, 2020).
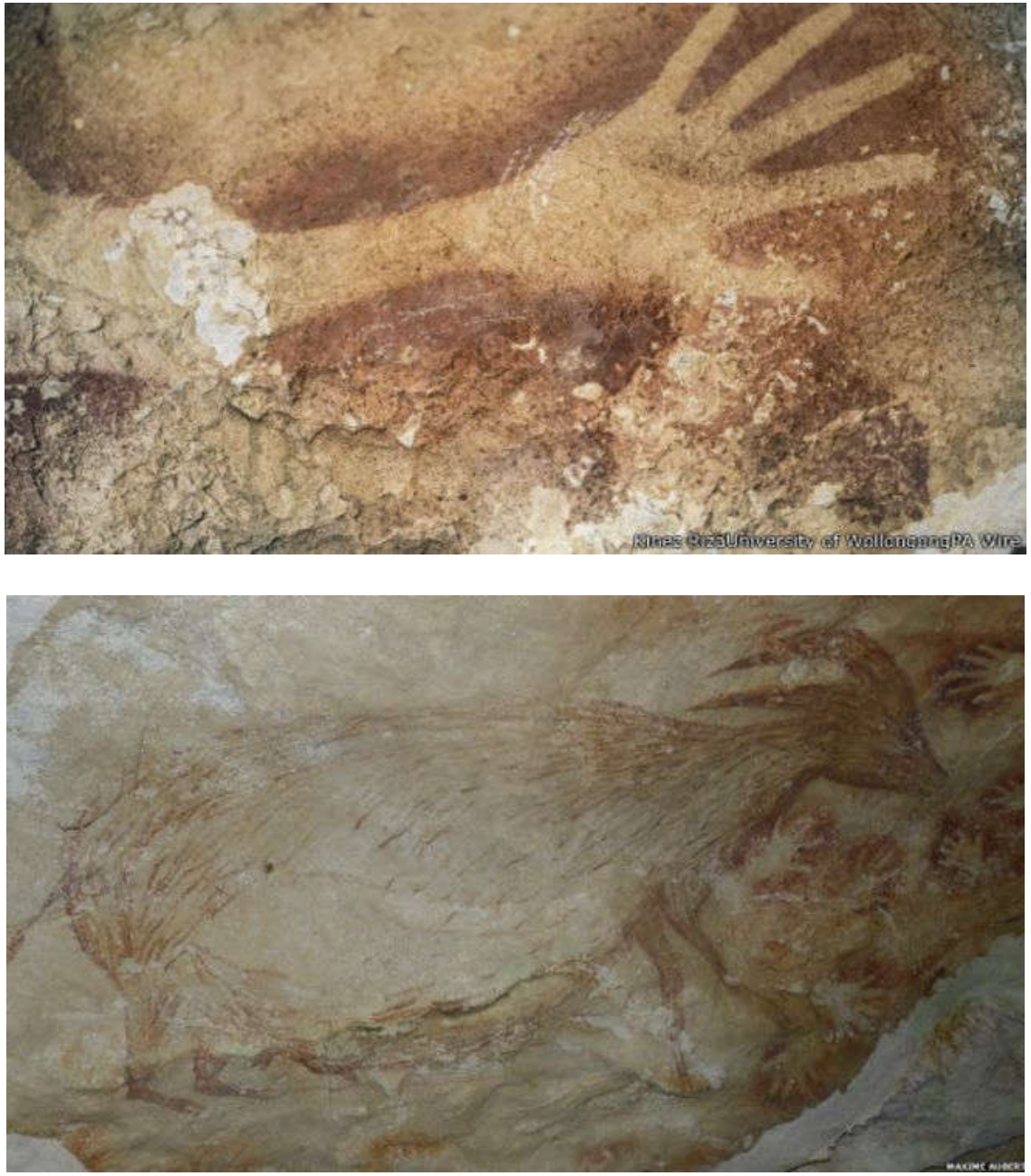

Gambar 1. Lukisan tangan dan binatang di Maros Sulawesi Selatan

Mural sebagai bagian dari Program Pengabdian Kepada Masyarakat (PKM) merupakan salah satu implementasi dari Tri Dharma Perguruan Tinggi. Melalui program mural ini diharapan civitas akademika bisa memberikan kontribusi bagi masyarakat dalam mendukung program pemerintah dalam hal ini adalah sosialisai Perilaku Hidup Besih dan Sehat (PHBS) yang dicanangkan oleh Pemerintah Kota Tangerang. Melalui PKM ini diharapakan terjalin kerjasama dan sinergitas antara civitas akademika, peneliti, pegiant kemasyarakat, pemerintah dan masyarakat. 


\section{METODE}

Tempat lokasi pelaksanaan program mural Pengabdian Kepada Masyarakat (PKM) ini di kecamatan Karawaci. Lokasi ini merupakan kawasan padat penduduk maka media atau tembok rumah warga (atas seijin pemilik rumah) menjadi media untuk dilukis mural. Lokasi mural mengambil spot/tempat yang strategis misalnya di pinggil jalan, pintu masuk pemukiman dan lokasi terbuka lainnya.

untuk:

Program Mural sebagai Pengabdian Kepada Masyarakat (PKM) ini bertujuan

1. Implementasi dari Tri Dharma Perguruan Tinggi bidang pengabdian Kepada Masyarakat.

2. Menjalin kenjasama dan sinergotas anatara sivitas akademika dengan pemerintah setempat dan warga masyarakat.

3. Memberikan kontribusi yang nyata bagi masyarakat sebagai salah satu pemengku kepentingan dalam perguruan tinggi.

4. Ikut mambantu pemerintah Kota Tangerang dalam sosialisasi Perilaku Hidup Bersih dan Sehat (PHBS).

5. Membangaun rasa kepedulian civitas akademika terhadap lingkungan dan masyarakat.

\section{Waktu Dan Pelaksanaan}

Pelaksanaan dari program Pengabdian Kepada Masyarakat (PKM) ini adalah:

Waktu : $01-31$ Agustus 2019

Lokasi : Karawaci Kota Tangerang, Banten

Tabel 1. Waktu Pelaksaanan PKM Mural Dinding

\begin{tabular}{|l|c|c|c|c|}
\hline \multicolumn{1}{|c|}{ Minggu/Kegitan } & $\begin{array}{c}\text { Minggu I } \\
\text { Agustus } \\
2019\end{array}$ & $\begin{array}{c}\text { Minggu II } \\
\text { Agustus } \\
2019\end{array}$ & $\begin{array}{c}\text { Minggu III } \\
\text { Agustus } \\
2019\end{array}$ & $\begin{array}{c}\text { Minggu IV } \\
\text { Agustus } \\
2019\end{array}$ \\
\hline Perijinan & $\mathrm{V}$ & & & \\
\hline $\begin{array}{l}\text { Survei lapangan dan } \\
\text { persiapan bahan } \\
\text { material mural }\end{array}$ & & $\checkmark$ & & \\
\hline $\begin{array}{l}\text { Sketsa/Gambar dan } \\
\text { Proses Mural }\end{array}$ & & & $\mathrm{V}$ & $\mathrm{V}$ \\
\hline $\begin{array}{l}\text { Proses Mural dan } \\
\text { finishing }\end{array}$ & & & & $\mathrm{V}$ \\
\hline
\end{tabular}

\section{Alat dan Bahan}

1. Perlengkapan melukis: kuas, cat dan tiner.

2. Amplas untuk meratakan dinding sebagai media mural.

3. Cat dasar warna putih untuk membuat dasar dinding supaya tidak meyerap cat berlebihan.

4. Cat minyak sesuai dengan warna mural yang diinginkan.

5. Cat glossy sebagai pelapis akhir mural supaya tidak mudah terkelupas oleh cahaya matahari dan air hujan.

Proses membuat lukisan pada dinding atau mural sifatnya tidak boleh dilakukan secara mendadak. Memerlukan perencanaan yang matang sehingga dapat menghasilkan mural yang baik. Ada beberapa persiapan yang perlu dilakukan saat hendak membuat mural, yaitu:

\section{Membuat jadwal persiapan}

Sebelum mulai eksekusi untuk membuat mural sebaiknya dipersiapkan waktu terlebih dahulu untuk persiapan agar tidak ada hal sekecil apapun yang tertinggal. Karena jika 
mengabaikan hal yang kecil-kecil dan cenderung terburu-buru, maka hasilnya terlihat lebih kotor, bahkan garis warna jadi tidak rata.

\section{Menyiapkan Semua Peralatan yang Dibutuhkan}

Meskipun mirip seperti melukis, proses pembuatan mural akan membutuhkan banyak sekali perlengkapan yang wajib dipersiapkan secara lengkap seusai pada kebutuhan.

\section{Memilih Konsep Gambar}

Mengenai konsep pada dasarnya ada banyak sekali yang bisa dipilih, apalagi mural biasanya dibuat sesuai pesanan pelanggan atau pelukis dapat memilih konsep yang paling sesuai dengan selera.

\section{Tutup Bagian yang Tidak Dimural}

Pada saat membuat mural nantinya akan ada banyak cat yang berceceran pada lantai, oleh sebab itu sebaiknya diantisipasi sejak awal. Tutup lantai dan bagian lainnya dengan kanvas atau koran. Kencangkan dengan perekat agar tidak bergerak, dengan begitu cat tidak akan mengotori bagian lainnyaa.

\section{Memastikan Dinding Siap di Mural}

Terakhir pastikan dinding untuk mural sudah siap. Jika memang keadaan dinding yang sebelumnya kurang mendukung, maka dilakukan secara mengamplas, menambal, mengecat ulang dan membersihkan dinding. Sebab dinding dasar juga akan sangat mempengaruhi hasil gambar mural. Beberapa hal di atas mungkin bisa Anda lakukan agar proses pembuatan mural bisa berjalan lancar dan hasilnya bisa lebih maksimal.

Sedangkan cara pembuatan mural PHBS adalah sebagai berikut:

1. Ijin pelaksanaan Pengabdian Kepada Masyarakat (PKM).

2. Koordinasi dengan pihak terkait dan lokasi PKM.

3. Penentuan titik mural.

4. Sketsa dalam kertas atau komputer.

5. Sketsa pada dinding mural.

6. Melakukan pengecatan dasar.

7. Melukis atau menggambar mural PHBS.

8. Finishing dengan melakukan pengecatan dengan cat akhir yaitu cat tipe glossy.

\section{HASIL DAN PEMBAHASAN}

\section{Manfaat Mural PHBS}

1. Sebagai media sosialisasi bagi warga masyarakat terhadap pentingnya hidup sehat dengan menerapkan Perilaku Hidup Bersih dan Sehat (PHBS) dalam hidup seharihari.

2. Membantu pemerintah kota Tangerang dalam memwujudkan Gerakan Tangerang Sehat

3. Membangun sinergitas antara civitas akademika dan masyarakat dalam mewujudkan kebersihan lingkungan dan memanfaatkan media berupa dinding sebagai media mural PHBS.

4. Lokasi mural PHBS bisa merubah lokasi yang awalnya kumuh menjadi bersih dan lebih enak dipandang bahkan bisa menjadi area swafoto.

5. Melalui kegiatan mural ini partisipasi dan gotong royong warga masyarakat menjadi modal yang penting, karena dengan support masyarakat penentuan lokasi mural mudah dilakukan.

Langkah pertama atau tahap ke 1 pelaksanaan pembuatan mural adalah penentuan lokasi dan persiapan pembuatan mural. Kegiatan ini dapat dilihat seperti pada Gambar 2. Sedangkan tahap ke 2 adalah melakukan sketsa pada dinding yang sudah ada cat dasar berwarna putih. Tahap ke 3 adalah melakukan sketsa gambar tertentu pada dinding yang sudah ada cat dasarnya seperti pada Gambar 3. Tahap ke 4 adalah Pengecatan mural PHBS secara lengkap seperti pada Gambar 4. Tahap ke 5 adalah finishing akhir dengan cat glossy seperti pada Gambar 5. Perbedaan dinding sebelum digunakan melukis mural dan 
setelahnya dapat dilihat pada Gambar 6. Sedangkan berbagai bentuk mural yang lain sebagai hasil dari PKM ini dalam rangka mendukung PHBS dapat dilihat pada Gambar 7.

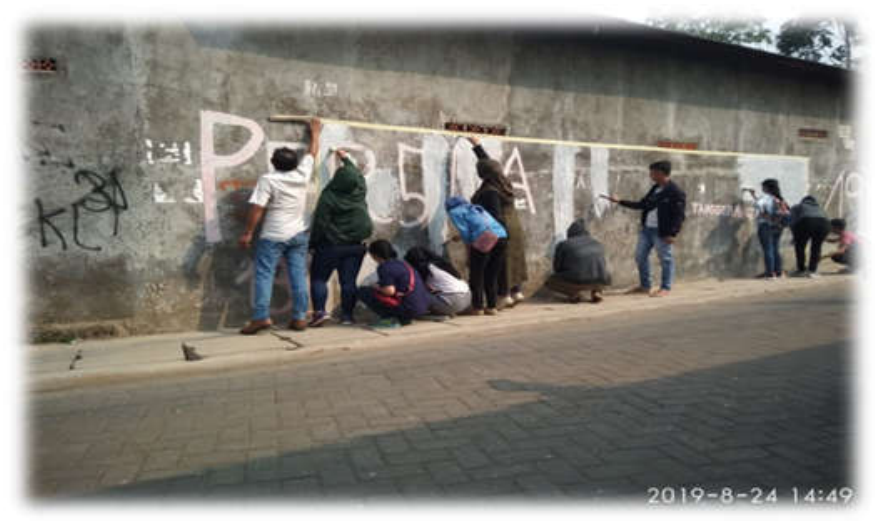

Gambar 2. Penentuan Lokasi dan pengecatan dasar

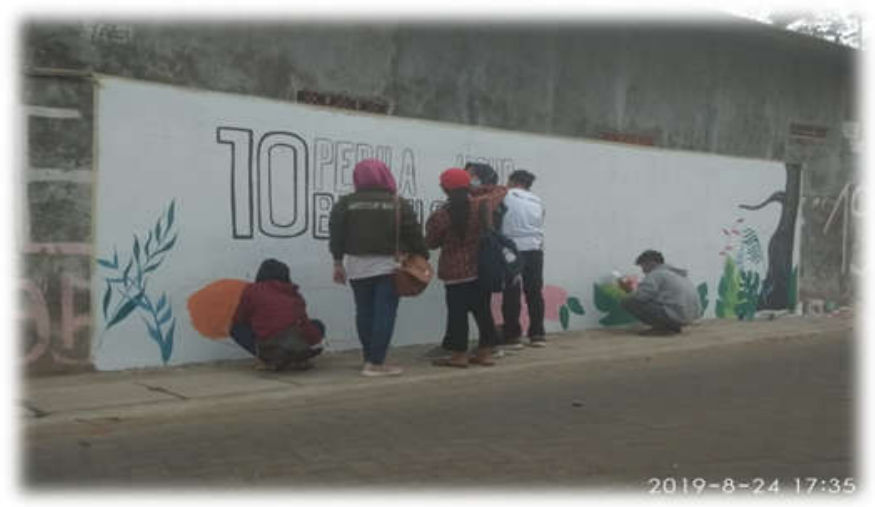

Gambar 3. Melakukan sketsa pada dinding yang sudah ada cat dasarnya

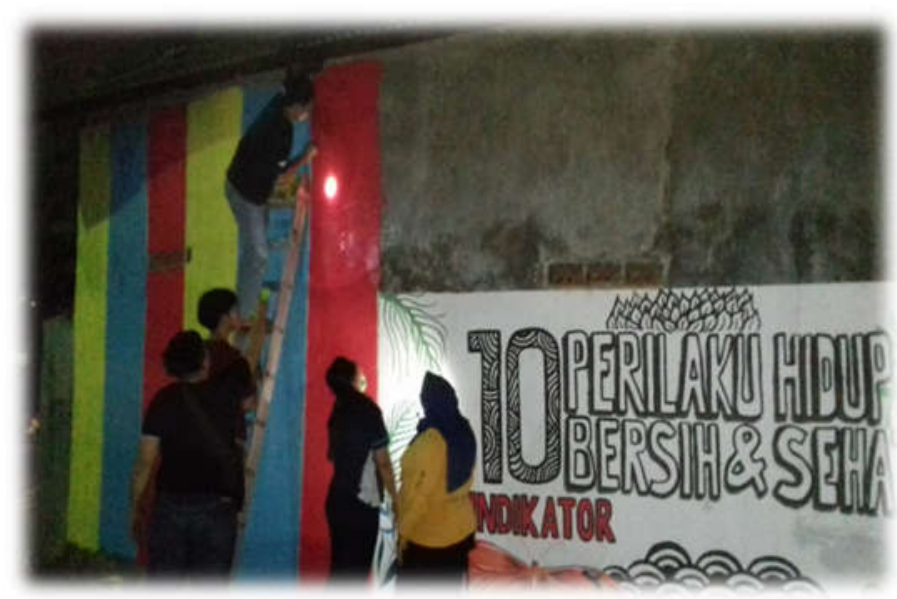

Gambar 4. Pengecatan mural PHBS secara lengkap 


volume 3 Nomor 2, oktober Tahun 2020

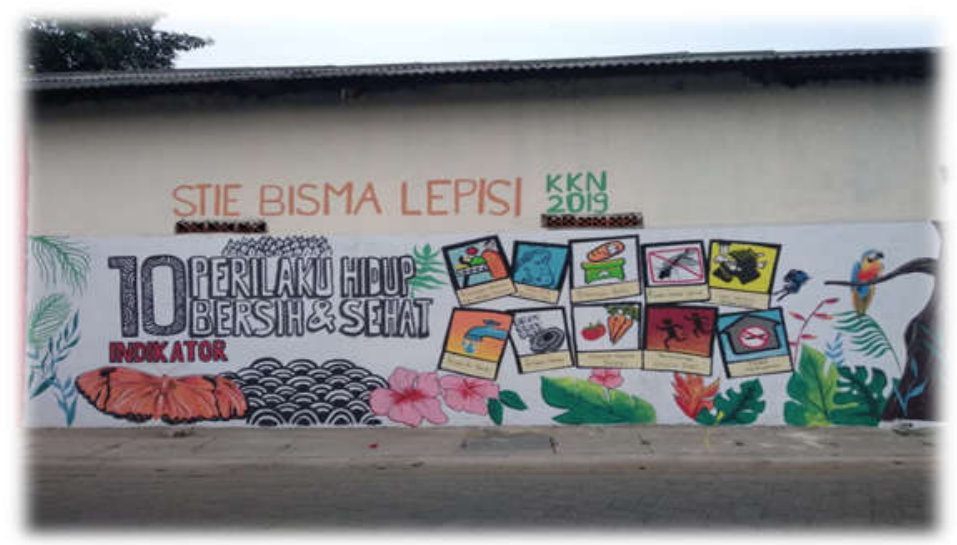

Gambar 5. Finishing akhir dengan cat glossy

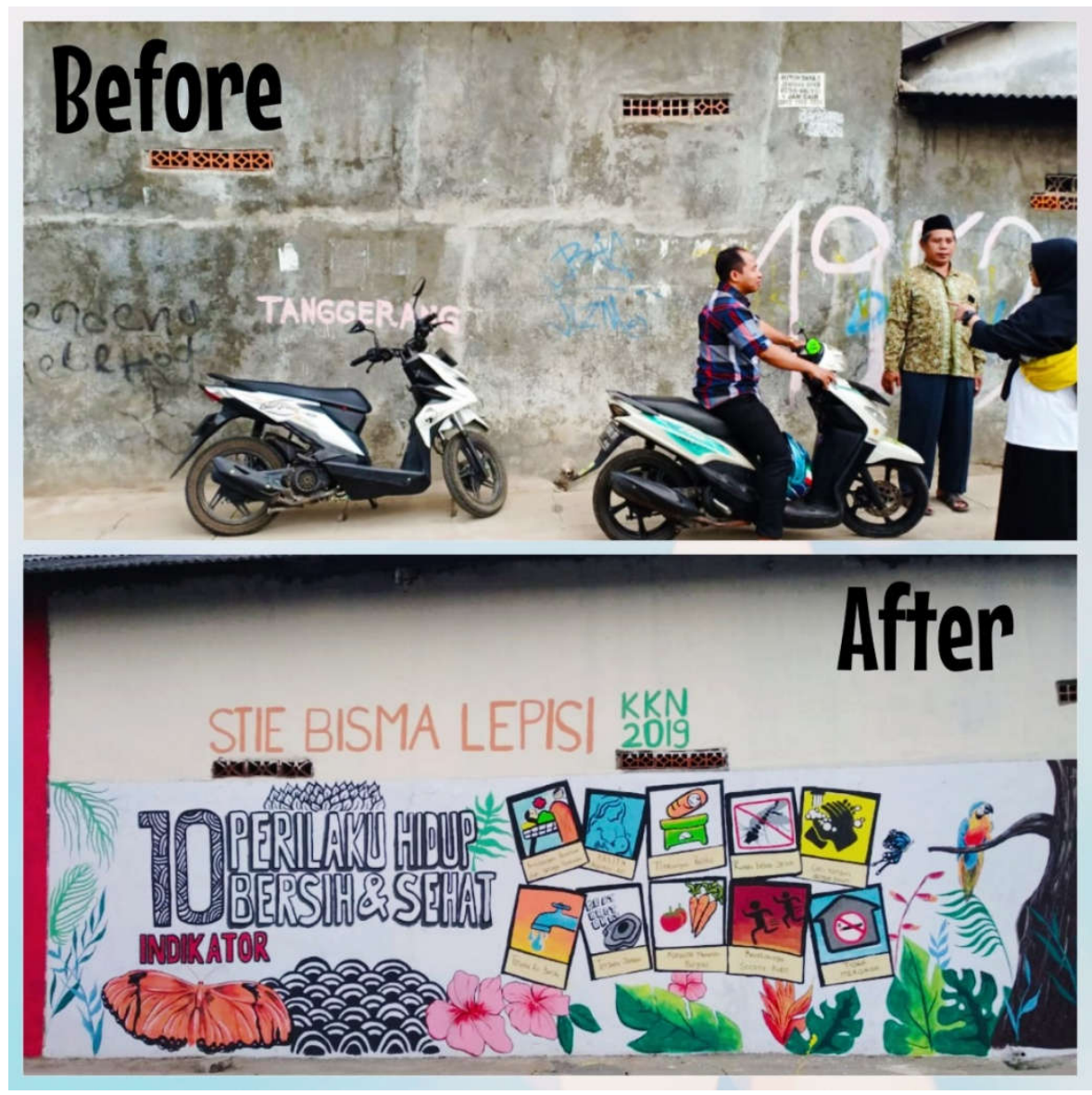

Gambar 6. Dinding sebelum dan sesudah diberi mural 

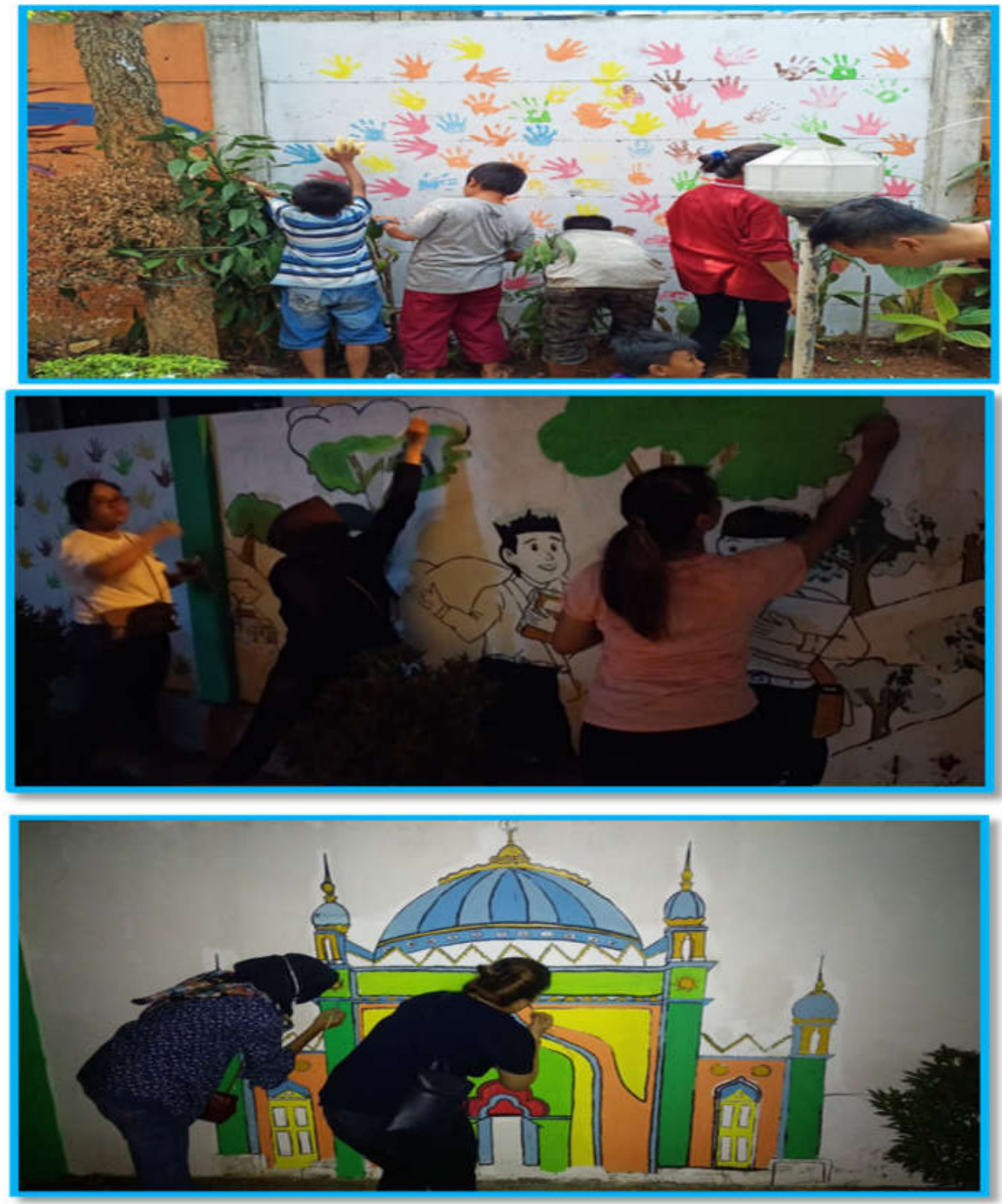

Gambar 7. Berbagai hasil Mural mendukung program PHBS

\section{DAMPAK DAN MANFAAT}

Dampak dan manfaat mural PHBS Kecamatan Karawaci, Kota Tangerang ini adalah:

1. Lokasi yang awalnya tidak bermanfaat bahkan kumuh bisa menjadi bersih dan bermanfaat.

2. Dengan adanya mural PHBS maka masyarakat selalu diingatkan untuk berpeliaku hidup sehat.

3. Melalui sosialisasi langsung secara tatap muka dengan warga dan dengan media mural PHBS maka bisa membantu Kecamatan Karawaci mendapatkan predikat bebas ODF (Open Defecation Free) atau kondisi ketika setiap individu dalam komunitas tidak buang air besar sembarangan dari dinas kesehatan.

4. Lokasi mural bisa menjadi swafoto da rekreasi kecil bagi warga.

5. Pemanfaatan dinding ruma wakga dan pemilihan lokasi yang tepat ternyata bisa memperindah lingkungan dan menjadikan pendorong warga masyarakat untuk berperilaku hidup bersih dan sehat. 


\section{KESIMPULAN}

Program Pengabdian Kepada Masyarakat (PKM) dengan Judul Mural Sebagai Sosialisasi Perilaku Hidup Bersih Dan Sehat (PHBS) di Kecamatan Karawaci Kota Tangerang merupakan pengabdian masyarakat dengan tujuan untuk membantu pemerintah Kota Tangerang dalam sosialisasi PHBS bagi masyarakat Kota Tangerang. PKM Mural ini memanfaatkan tembok dinding rumah warga dengan melakukan lukisan bertema PHBS dengan 10 indikator PHBS. Sosialisasi PHBS dilakukan secara tatap muka dengan warga maupun menggunakan media. Mural merupakan salah satu media sosialisasi. Dengan adanya mural PHBS diharapkan warga selalu diingatkan untuk memiliki pola hidup sehat dengan menerapkan Perilaku Hidup Bersih Dan Sehat baik di pribadi, lingkungan keluarga dan masyarakat.

\section{UCAPAN TERIMA KASIH}

1. Ketua STIE Bisma Lepisi beserta jajarannya yang telah mendukung PKM ini.

2. Para mahasiswa STIE Bisma Lepisi sebagai relawan PKM.

3. Pemerintah Kecamatan Karawaci Kota Tangerang atas ijin dan kerjasama yang baik.

4. FKTS (Forum Kota Tangerang Sehat)

5. Semua pihak yang tidak bisa disebutkan satu persatu, terimakasih atas kerjasamanya yang baik.

\section{REFERENSI}

Endriawan, D., Maulana, T. A. and Sadono, S. (2017) 'Mural sebagai Media Pendidikan dan Pengabdian Masyarakat', in. Seminar Nasional Seni dan Desain 2017, State University of Surabaya, pp. 482-485.

Fatin, N. (2018) Mengenal Lebih Jauh Seni Mural. Pecinta Seni Harus Tau, Nih! Available at: https://www.hipwee.com/narasi/mengenal-lebih-jauh-seni-mural-pecinta-seniharus-tau-nih/ (Accessed: 12 August 2020).

Gazali, M. (2017) 'Seni Mural Ruang Publik Dalam Konteks Konservasi', Imajinasi: Jurnal Seni, 11(1), pp. 69-76.

Ifwandi, N. (2020) Pengertian Mural,Sejarah,Perkembangan \& Perbedaan Mural dan Graffiti. Available at: https://www.imural.id/blog/pengertian-mural/ (Accessed: 12 August 2020).

Lilih, P. (2009) 'Mural Art Center di Jogjakarta: Merancang Mural Art Center dengan Pendekatan Metode Perancangan Partisipatif'.

Luthfi, W. (2020) Perbedaan Mural dan Graffiti, Gambar yang Percantik Gang dan Jalanan | Good News From Indonesia. Available at: https://www.goodnewsfromindonesia.id/2020/03/19/perbedaan-mural-dan-graffitigambar-yang-percantik-gang-dan-jalanan (Accessed: 12 August 2020).

Suastika, I. (2018) 'Perancangan Buku Ilustrasi Dan Infografis Perkembangan Dan Fungsi Mural Di Yogyakarta'.

Williamson, G. (1999) 'Decorative murals with Donna Dewberry.' 